DOMINIKA KACZOROWSKA-

SPYCHALSKA

\title{
How chatbots influence marketing
}

Dominika Kaczorowska-Spychalska, Ph.D., University of Lodz, Faculty of Management, Department of Marketing, Poland, ORCID: 0000-0002-2566-0297.

\section{Introduction}

Nowadays digital technologies become a catalyst of subsequent stages of the evolution towards the transformation of current paradigms and solutions based on them. Innovations that are their consequence create a wide range of possibilities while changing our cognitive processes and efficiency of related actions. Robotization of processes, cognitive automation or social robotics evoke various implications in terms of individual business models along with their new attributes. Their etiology decides about a possibility of further commercialization. They enter new functional areas connected with a current organization activity while increasingly taking over decisive competencies, and they influence a level of market flexibility of companies/brands and their operational efficiency. As a result, the digital revolution has reached a scale and level of impact that no business, industry or government can ignore. The future countries, business and individuals will depend more than ever on whether they embrace digital technologies, which can break down geographic, cultural and personal barriers in amazing new ways (Lubian, Esteves, 2017, p. 1).

We live in an epoch of information overload. In spite of the fact that the basic principles

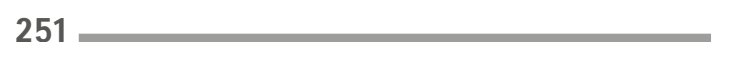


of marketing will remain the same, to a much greater extent they become individualized and contextualized, enabling brands to convert their current market orientation. The multiplicity of media and related channels enforces the need to process messages and stimuli in a constant and uninterrupted way. In such an approach the upgrade connected with digital technologies becomes an inherent element of marketing while allowing various market players to join in an easier and more integral way than ever before. Using chatbots in that process enables companies/brands to intensify consumer's diverse emotions and experiences while increasing their involvement and satisfaction. They becomes smarter and more cognitive in the space of algorithmic economy.

The objective of the article is to identify opportunities connected with using chatbots in marketing, with particular focus on their role in the process of Human - to - Machine interactions. Part One describes the most important challenges that the development of digital technologies poses to companies/brands, frequently enforcing reconfiguration of their current practice and redefinition of the shaped market intelligence. The subsequent part presents the definition and essence of chatbots and their role in marketing. Conducted discussion is one of the elements of initiated studies on the impact of digital technologies (the Internet of Things and Artificial Intelligence) on the directions and dynamics of the development of the Digital Society (in its individual dimensions - a model of interaction between a man and technology).

\section{Marketing with digital technologies}

The number of web-enabled devices is steadily increasing, which is reflected in a number of based solutions in industry, marketing, commerce, agriculture or public administration. The key technologies in 2019 primarily include the Internet of Things (IoT), Artificial Intelligence (AI), Big Data, Augmented Reality, blockchain and Internet 5G. According to Gartner's Hype Cycle for Emerging Technologies 2017 and 2018, the IoT and AI will have the biggest impact on the pace of economic development of many countries in the coming years. Factors conducive to their absorption in business, consumer and social dimensions certainly include the growth of functionality of devices, equipment, systems and applications based on these technologies. On the one hand, they become a factor stimulating the development of new solutions that are their consequence, and at the same time, as a specific DNA code of the digital economy, they undergo constant processes that enhance their potential. Now we have some series of new technological moments that creates other new technology, technology 
that creates the need for other new technology that then includes customers as a part of it (Wuebben, 2017, pp. 85-93). As a result, new better versions of current solutions, new functions and updates will appear and they will lead to a gradual, albeit constant process of improvement (so-called protopia by Kevin Kelly).

The digital structure of values functions in real time, it is global and connected. It comprises more than seven million people communicating and trading in real time by means of the web along with a few billion of devices which have a built-in artificial intelligence and which belong to these people (Skinner, 2018, p. 31). While intertwining links and radio waves our species started to connect all parts of the world, all processes, all people, all artifacts, all sensors, all facts and notions into one huge network of the scale of complexity that was previously unthinkable. A common interface of our civilization has come into being. This is the unity that penetrates through our life to such an extent that it becomes indispensable for our identity. Then, that enormous structure provides a new paradigm of thinking and "a new mind" (Kelly, 2017, p. 404). Digital transformation definitely becomes unavoidable and leads to the specific technium - the modern system of culture and technology that accelerates a creation of new, impossible things while developing new ways of social beahaviour. Computers and other digital advances use the ability of our brains to understand and shape our environments. They are allowing us to blow past previous limitations and taking us into new territory (Brynjolfsson, McAfee, 2014, p. 6). It leads to the transformation from conventional processes of digitalization to increasingly multidimensional forms and tools of adaptation of individual digital technologies and their combination. As a consequence, stronger technological, humanistic, psychological or moral permeation appears, and it enforces a need to redefine current activities. The resulting convergence leads to bipolarity of observed phenomena: dehumanization of business and humanization of technologies. Yet, it may be assumed that their dynamics will lead to gradual entropy enabling more unified separation of space of interaction at four equivalent levels: Human - to - Human (H2H), Machine - to - Machine (M2M), as well as Human to - Machine (H2M) and Machine - to - Human, which are a hybrid solution. Omnipresence of interactions with technology will become an attribute of civilization infrastructure, and a blurred boundary between what typically belongs to a human and what is a symptom of technology, will deepen an already visible need to look at the market in a holistic way.

The world is changing around us - new technologies, new competitors, new capabilities, new regulations, new quality issues that need to be addressed, new 
customers, new marketing approaches to attract customers to develop insights that can develop into the whole new business models (Saacolick, 2017, p. 5). Currently, it is assumed that digital technologies can result in an increase of functionality of applied solutions, growth of operational effectiveness along with improvement and optimization of implemented processes and tools in an individual enterprise. They are to facilitate everyday activities as well as to improve a standard and quality of life, especially if they are analysed within integrated ecosystems. In such space marketing is subject to stronger and stronger technologization processes while evolving towards algorithms, predictive marketing based on them, solutions using so-called MarTech or, ultimately, marketing based on values that are integrated with everyday consumer lifestyle. Digital transformation brings on a new wave of projects that have technology enablers, require new digital workflows and ideally have new ways to service customers. They include integrating marketing automation tools, deploying upgraded mobile applications to customers or enabling new data analytics capabilities through Big Data technologies (Sacolick, 2017, p. 130). Consequently, marketing in the digital era combines online and offline interactions, blends a style with the essence and supplements connection between machines with human interaction in order to strengthen consumer involvement (Kotler, Kartajaya and Setiawan, 2018, p. 63). Therefore, it requires an incremental approach conditioned by dynamics of observed changes, leading to integration of three main components: unique values that an enterprise/brand represents, expectations and desires of consumers as well as new models and tools of meeting them. It is heading for an analytical activity based on mathematical formulas while multiplying benefits in the area of consumers' conceptual and emotional intelligence.

By 2030 we can expect in the marketing practice:

- ubiquitous Internet in the air around us (most will be unseen),

- widespread Internet of Things (more senses, more intimacy, more immersion),

- Artificial Marketing Intelligence,

- immersive experiences (immersive brand experiences, more interactive advertising, etc.).

As a consequence, we will have to deal with: hyper targeting, automation of the shopping experiences, easy exchange of sales data, smarter CRM (instantaneous customer analysis), predictive social media, new ad and content forms (e.g. personalized advertising or gladvertising), omnipresent personal assistance, chatbots and maybe cyborgs (Daugherty, Wilson, 2018, p. 188). Moreover, digital technologies will be affecting the customer relationship with corporations 
and brands, which can save customers time and effort and can help provide customizable experiences and products, cutting back on a lot of advertising (Daugherty, Wilson, 2018, pp. 86 -90).

Filtering algorithms organize contents, filter them and offer consumers the ones that have a chance to be noticed while leading to a conclusion of transaction. In spite of the fact that filter bubble polarizes our way of thinking and preferences, simultaneously, it helps to systematize them. Sophisticated algorithms help customers find items based on presumed relevance. Human customers reviews, performance data, filtering algorithms and revenue and profit maximization techniques that optimize based on financials and propensity to purchase become the new embodiment of intimacy (Weinman, 2015, p. 175). That entails a need for changes in customer service and a process of building their satisfaction as a result of experiences generated in interactions with machines (quantity, quality, depth of experiences). Understanding a consumer is definitely a key element of market orientation of modern enterprises/brands. While taking social dynamics into consideration, digital marketing becomes an inspirer of integration of all experiences faced by consumers so that they can be involved in interactions with a brand by means of digital technologies.

Digital consumer is mobile, well-informed and superbly functions in multichannel space while showing a high level of competence and skills connected with new technologies. They place stronger requirements on enterprises/brands while expecting openness, transparency and authenticity. They want to remain in contact with them and to have a choice of used channels, methods and tools of establishing and keeping that contact. This consumer became a native consumer: very active in hypermedia space, intensely buys online, spends a lot of time online. These are no longer single episodes there are numerous transactions or other points of contact and multiplicity of overlapping interactions. What is of crucial importance is what a consumer does, says, feels - it is not only a buyer any more, first of all, it is a human that collects experiences, emotions and sensations (Gregor, KaczorowskaSpychalska, 2018, pp. 71-76). Nowadays consumers are discoverers that look for deep sensations in constant experiencing. They consume mainly values, narrations and ideologies while living in the world of information and content. Access to digital technologies increasingly determines their personality and behaviour. Evolution definitely has not stopped at Homo Sapiens - there is still a long way of development before us. Mankind will gradually become increasingly stronger and better adjusted, probably leading to the emergence of so-called singularity that has better capabilities, which is reflected in creating 
new knowledge and more advanced technology while moving steadily from the idea of homocentrism to the idea of danocentrism (Harari, 2017, p. 321). As a consequence, a profile of a new digital consumer - Homo Cyber Oeconomicus - is a kind of cluster of various dimensions of contemporary human evolution towards a way of thinking which is mostly influenced by the observed current changes, in particular, determined by the digital revolution (Homo Sapiens, Homo Economicus, Homo Cyber, Homo Transgressive, etc.). The more a consumer becomes one of the links of technicization, trusting not only own feelings but also algorithms that will know better what they want and desire, the more they will balance between what is behavioral and what is cognitive, between humanism and dataism, between what will sustainably connect them with technology and what will make them different.

So, digitization is one of the most important phenomena of recent years, which entails a range of new opportunities, also in marketing, thanks to which our current knowledge undergoes constant deepening while allowing to understand the past better and to predict the future more precisely. However, it also entails new challenges. Skeptics of digital technologies, artificial intelligence, in particular, perceive them in the context of dystopian vision of the future. The moment we as humans lose relevance for the Web functioning, it may turn out that we are not the crown of creation. We may sink into oblivion. When we turn back, it may prove that the mankind was only a tiny wave in the cosmic flow of data (Harari, 2017, p. 502).

\section{Role of chatbots in marketing}

Digital technologies have gone beyond the limits of what we used to consider as an imminent feature of a human being. It should be noted that they show a wide range of competencies such as recognition of images, thought patterns, making decisions, communication, adjusting the context of a statement to a situation, etc., while engaging us in a fascinating journey into the unknown. As the research shows, interest in using chatbots, which are one of the symptoms of digital transformation, steadily increases in marketing activities of companies/brands. Although chatbots have been developed since 1950, only in recent years companies have started using them to communicate with clients and potential clients (State of Chatbots Report 208, p. 6).

A chatbot (also known as a talkbot, chatterbot, Bot, IM bot, interactive agent, or Artificial Conversational Entity) is a computer program which conducts 
a conversation in natural language via auditory or textual methods, understands the intent of the user, and sends a response based on business rules and data of the organization (https:// chatbotsmagazine.com/chatbot-report-2018-globaltrends-and-analysis-4d8bbe4d924b, access: 10.02.2019). It performs various functions replacing a man and pretends human behaviour. Together with subsequent experience it learns while extending its communication competencies and develops knowledge how to personalize a message and improve own rules of communication and reactions. These are complex interfaces based on the analysis of a natural language and interpersonal communication rules, which enable better human-machine interactions and a conducted dialogue is purposeful and defined (Przegalińska, 2016, p. 33). As a result, chatbots are able to answer given questions, provide answers, solve problems while understanding users' intentions. So, a chatbot becomes a technological reflection of a man, which leads to dehumanization of what is human and humanization of technology along with its manifestations (more human than human).

According to the experts of K2 Digital Transformation agency Internet bots account for more than $50 \%$ of all online traffic including website browning, publication of content, media playback or downloading files. According to Gartner's expectations by 2020 an average Messenger user will be more often talking to bots than to a partner every day, and $85 \%$ of interactions between a client and a brand will not be based on a direct contact with a human. Moreover, at the same time more than $50 \%$ of middle-sized and big global enterprises will implement solutions based on chatbots, mainly conversational ones, which will result in, as foreseen by Grand View Research, the growth of global chatbot market value to 1.23 billion dollars in 2025 .

Bots used in marketing strategy can prove to useful in activities implemented in social media space while suggesting specific contents or a way of interpretation and understanding reality. Their personality, generally understood as a way in which they conduct conversations, a style of behaviour, a form and range of used universal phrases and sayings, etc., can intensify consumers' experiences and emotions desired by a company/brand while influencing their purchasing decisions and market behaviour. A well-prepared chatbot of charming personality that will efficiently lead a buyer through subsequent stages of transactions while saving their cognitive effort and time, may become a key value distinguishing a given brand from its competitors. It is definitely more sociable, friendly and real than current market applications, especially in a way it establishes contact, conducts a conversation or makes an attempt to build a relation. While aspiring to be like people, chatbots must become human because 
we expect human behaviour and reactions. The most advanced ones are able to advise buyers and suggest specific choices (products, services, brands) before they realize their needs and expectations themselves. According to estimates, more than $67 \%$ of consumers worldwide used a chatbot for customer support in the past year and $40 \%$ do not care whether a chatbot or a real human helps them, as long as they are getting the help they need (https://www.invespcro.com/ blog/chatbots-customer-service access: 10.02.2019). In turn, according to the data of the SMSAPI report, almost 53\% of respondents in Poland are satisfied with such a form of interaction although $29 \%$ of the surveyed admitted that a bot did not solve their problem. At the same time, 34\% of respondents were not satisfied with the course of conversation regardless of its result (SMSAPI 2018). Yet, this is optimistic information for companies/brands which allows them to think about chatbots as a tool that will result in better effects than activities based on traditional advertising, while simultaneously stimulating a brand prestige as an innovative one following changing consumer expectations. Thanks to that chatbots work perfectly in processes of broadly understood customer service, sales processes or complaint procedures. They are efficient in recommendation systems, obtaining sales leads or ultimately popularization of entertaining content offering an enjoyable and interactive way of contacting a company/brand. Chatbots can save up to $30 \%$ in customer support cost and can help businesses save on customer service costs by speeding up response times and answering up to $80 \%$ of routine questions. (https://www.invespcro.com/blog/chatbotscustomer-service access: 10.02.2019). Phone calls, emails and even beautiful web forms will not be able to afford a split-second reaction, which is given by majority of present-day chatbots (https://chatbotsmagazine.com/chatbot-report-2018global-trends-and-analysis-4d8bbe4d924b access: 10.02.2019). So, it improves the speed and effectiveness of implemented marketing activities. Chatbots can also prove useful in internal marketing, especially in recruitment or training processes as well as support for specific marketing goals, tools and strategies. They are able to provide necessary information about activities of competitive companies, consumer preferences or key market trends. It is confirmed by the results of "State of Chatbots Report 2018"study.

According to the TogetherData analyzes, the biggest demand for solutions based on chatbots will be visible mostly in e-commerce, insurance, financial consulting and telecommunication. Nowadays, in these sectors there is the highest degree of chatbots' acceptance in consumers' opinions: e-commerce $34 \%$ of consumers, medical services $27 \%$, telecommunication services $25 \%$, banking services $20 \%$, insurance consulting $20 \%$. 


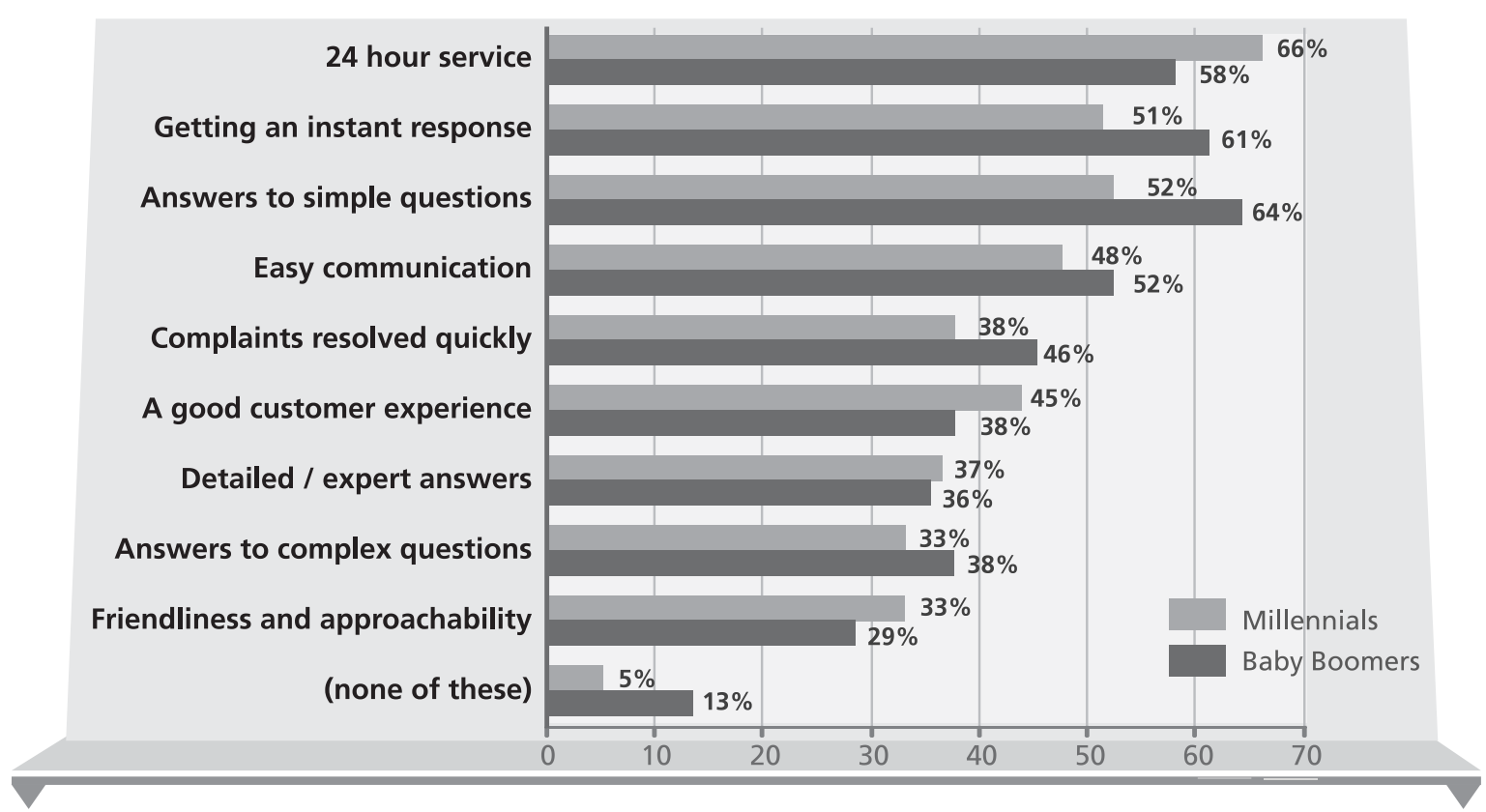

Figure 1. Potential benefits of Chatbots (Millennials vs. Baby Boomers)

Source: State of Chatbots Report 2018, USA

Nowadays, globally chatbots are used by such brands as for example: Bank of America, eBay, HEM, Pizza Hut, Samsung, Microsoft, Amazon, Subway, Zalando, whereas in Poland they include Alior Bank, Bank Millenium, ING Bank Śląski, Warta Insurance, Pizza Hut Polska, GPW, Tymbark, and many many others.

Nowadays a dominant type of chatbots in the market are the so-called rulebased chatbots whose role is limited to operating only in the range of specific, closed databases. Therefore, there are often skeptical opinions about chatbots' possibilities among the people who interacted with them, yet, the questions they asked went beyond the knowledge of a chatbot at a given moment. Bots are designed to be dynamic, able to learn and change, so companies/ brands must also determine what boundaries to set as their bots evolve over time (Daugherty, Wilson, 2018, p. 94). Further development of chatbots will be definitely connected with the dynamics of artificial intelligence (AI) development. Currently, we deal with the so-called narrow AI as it is limited to some human skills e.g. playing chess or driving a car. It does not enable a full representation of cognitive and emotional processes, which occur in human brain. However, research and work on its subsequent levels are ongoing (Tegmark, 2017, p. 39): 
- Universal Intelligence which has the ability to acquire general intelligence given access to data and resources,

- Human - Level AI/Artificial General Intelligence (AGI) which has the ability to accomplish any cognitive task at least as well as humans,

- Superintelligence which has general intelligence far beyond human level.

Experts think that there is a better than 10 percent chance AGI will be created before 2028, and a better than 50 percent chance by 2050 . Before the end of this century, it will be 90 percent chance (Barrat, 2015, p. 25). It will undoubtedly intensify the development of chatbots in a cognitive dimension while enabling them to recognize a wider context of statements, speaker's intentions as well as their emotions (today it is still considered impossible), which will allow companies/brands to use chatbots in marketing that are able to generate answers in an autonomous and untaught way, extensively extending their functional range. A growing number of available open source platforms and resources can also increase a number of solutions that will be directly designed and serviced by companies or brands using them (typical solutions based on the most popular functionalities) with simultaneous development of marketing services, agencies and media houses orientated at preparing and management of customized solutions (unique solutions). Currently chatbots are generally built on top of already existing messaging platforms such as Facebook Messenger or WhatsApp. Chatbots can put a company or a brand right where the action is - in chat and messenger apps like Facebook Messenger or Slack. That way customers and prospects can get the information and experience they seek where it is potentially most convenient for them (https://ducttapemarketing.com/chatbots-for-business access: 10.02.2019).

Experts are convinced that in the coming years we will increasingly often deal with the so-called social model of chatbot that will be able to select the most appropriate schemes of conducted conversation regarding recognized levels of social acceptance and market practice (accepted rituals, accepted behaviour, accepted rules). It will adjust to optimize a level of satisfaction while adapting and changing a style of its responses and conversation strategies, etc., while simultaneously keeping consistency between its technological and social dimension. Intensity of mutual interactions between a chatbot and a human-consumer will result in autonomous changes of the whole system of such interactions as participating in reciprocal experiences, changes in behaviour of one party will be a result and consequence of changes in the other party's behaviour. It can foster synchronization 
processes of work of chatbots and employees within individual departments or groups of posts as complementary ecosystems. Yet, it is necessary to divide these areas explicitly so that work of chatbots is not competitive for a man, but is its real supplement and support. AI doing what it does best (sifting through and processing copious data to recommend certain actions) and humans doing what they do best (exercising their judgment and social skills to help customers purchase products that better fit their needs) (Daugherty, Wilson, 2018, p. 90). As a result, chatbots are expected to cut business costs by $\$ 8$ billion by 2022, being the most potent weapon in the arsenal of businesses, promising massive revenue (https://www.forbes. com/sites/forbestechcouncil/ 2018/08/29/chatbots-a-powerful-weapon-inthe-business-arsenal/\#41580cf64960 access: 09.02.2019). Therefore, it can be assumed that companies/brands while trying to optimize their profits will endeavor to create specific networks in which chatbots could realize assigned functions while remaining in interaction and cooperating only with other bots. As a result, a role of a human would be to a greater extent directed towards straight programming activities, controlling and managing such systems (e.g. chatbot manager, chatbot trainer, etc.). Interestingly, it is more often said that chatbots will not only be relevant in business or consumer terms but will also influence the further development of the Digital Society. Experts predict that by 2050 it will be common practice to leave a chatbot behind that will speak like we did, will know our stories from the past and comfort our family after our death. Such "digital doubles" will also appear instead of the living. Celebrities will use bots to create their presence in social media, to respond to messages on Facebook and put photographs and signatures on Instragram. They can also organize meetings, social events or reply to emails. This will be a kind of digital outsourcing of our life and life after life (Walsh, 2017, p. 242). It will definitely increase requirements from opportunities that chatbots will offer, enforcing on companies/brands a need to systematically implement or multiply functionality that they will be able to realize that way.

The evolution has created people, and people created technologies, at the same time using them to create their successive generations. This causes that the technological evolution is continuation of the biological evolution. Homo Sapiens evolved only in several hundred thousand years and the technology they created needs only dozens of thousands of years to be fully shaped and ready for widespread use (Kurzweil, 2016, pp. 53-55). However, it is hard to predict whether the observed changes will be of homogenous nature. They will rather 
be diversified, depending on industry and market sector, a level of maturity of companies/brands towards digital technologies and a degree of their social acceptance.

\section{Preliminary assumptions of the model of interaction between a consumer and chatbots (digital technologies) in marketing}

Digital technology and the Internet gave us precious resources: new media, a new world of cultural practices which do away with the clear -cut distinction between creators and their audiences, producers and consumers to enable all to appropriate these new practices, and to promote quality in activities conducted in common (Aigrain, 2012, p. 22). Consequently, it can be assumed that observed dynamics and directions of the development of digital technologies, their diversity and a degree of market absorption (actual implementations - companies/brands, areas of applications) are strongly related to human behaviour, especially as a consumer, influencing their preferences, expectations and professed values.

The world in which we live now is a reflection of constructs and meanings, which acting as symbols are a semiotic reflection of the concepts or ideas accepted or rejected by the society or its selected segments. An accompanying effect of information metabolism determines an individual level, in which every man perceives and processes data, shapes their mental sphere, including emotions, while influencing their further cognitive activities. At the same time, the observed confirmation bias causes that a consumer shows an inclination to prefer information that is in line with their previous experiences, professed values or convictions, which results in selectivity of received information. As a result, a consumer may totally reject opportunities that using digital technologies brings to marketing, in particular with respect to its specific applications (e.g. chatbots, wearables, etc.) or interpret them wrongly. The result will be even stronger, the more extreme emotions and fears these technologies will evoke. The social acceptance of chatbots can be lower, as many human jobs will be replaced by machine labor (Borek, Reinold, 2016, p. 155). Resulting polarization of views may hinder a process of social acceptance of digital technologies and a pace of their penetration into practice. However, the already observed multiplicity of available "smart" solutions allows to suppose that digital technologies will contribute to increasingly bigger diversity and multi-polarity in companies/brands' approach to a consumer, especially toward Z generation representatives. As the research shows, including the study conducted within 
the scientific project funded by the National Science Centre called „The Internet of Things in the Process of Virtualization of Consumer Behaviour"1, this is the group of consumers that treat solutions based on digital technologies as something natural and obvious while indicating a greater degree of their acceptance and willingness to buy related products than in case of $Y$ generation representatives. According to the behavioral approach, technological environment steers a man, and simultaneously, a man shapes their technological surroundings and exerts impact. As a result, a consumer while remaining under the influence of companies/brands (various new stimuli reaching them by means of digital technologies), at the same time is able to independently apply these technologies in a process of creating new knowledge, in turn influencing the configuration of values and rules that companies/brands will use. In such an approach, digital technologies can become a specific catalyst of interactions between a company/ brand and a consumer.

A wide spectrum of potential functionalities and benefits that chatbots will generate in marketing causes that they will undoubtedly be a subject of deep interest in the coming years. The new customer interactions are seductive because there is upside for all-the proverbial win-win situation. The customer gets an evolving "product"(chatbot) that continuously meets its needs and the enterprises is motivated to improve its business to increase customer lifetime value (Sinclair, 2017, p. 69). It encourages to undertake a discussion that could result in formulating more or less advanced models referring not only to social acceptance of these technologies, but also to an interaction between a humanmachine and smart technology. Nowadays one can find in the literature (national and foreign) numerous examples of studies referring to the acceptance of new technologies enabling to explain and describe consumer's interest and engagement in various technologies and based solutions. It concerns, for example, using mobile Internet, e-commerce, m-commerce, electronic banking, e-learning or social media. The analyzed models and their successive modifications are justified in practice, providing the research basis with respect

1 The aim of the study was to identify ways and differences in perception, acceptance and use of devices based on the Internet of Things technology (IoT) among the representatives of $Y$ and $Z$ generations. It was conducted in the period between May 2018 to mid-January 2019 by means of a direct questionnaire. Ultimately the study comprised 3163 respondents (students) of the 1st year of the 1st cycle studies ( $Z$ generation representatives) and students of the 2 nd year of the 2 nd cycle studies ( $Y$ generation representatives), among the fields reflecting distinct scientific areas (as of February 2018): humanities, social sciences, exact sciences, natural studies, arts (the sampling was purposeful) studying in full-time and extramural programmes. 
to both, various industries and market sectors, diverse groups of consumers or different applications. They are also successfully used in studies concerning individual digital technologies (such as e.g. IoT, AI or their specific applications: Chatbots, Beacons or Digital Twins) or their ecosystems. However, human-digital technology interactions seem increasingly complex (we remain an element in that system), as a result, benefiting from achievements of various scientific areas and disciplines (biology, psychology, sociology, cybernetics, physics, industrial engineering, economics, etc.), they create their own standards, rules and values. Moreover, many areas of these dependencies are still unknown and/or unconscious - they will be shaped concurrently during deepening of symptoms and effects of digital transformation (e.g. variables that appear as a result of intensification of absorption of these technologies and their penetration into all areas of our human activity).

Human - to - Human interactions are now joined by Human - to - Machine and Machine - to - Human interactions. The network of these interactions is reliable, exceptional and very specific but also more fragile (Benz, Meikle, 2018, p. 46). Referring to the theory of computationism, it could be hypothetically assumed that it would be possible to model consumer's cognitive processes concerning chatbots and the range of their interactions with them, just like computers are programmed in an algorithmic way. Yet, such an approach raises ethical doubts and would be undoubtedly difficult to implement in market practice, and additionally, the theory of computationism was severely criticized. A much better approach in this case is connectionism approach, as a result of which a degree of consumer's interaction with chatbots in marketing would be a consequence of their gradual learning. At the core of this is then an association between a stimulus (activities of companies/brands) being a manifestation of digital technology, and a reaction of its recipient - consumer. Accompanying factors and brand behaviour e.g. awarding such behaviour with regard to chatbots that are desired by the brand (positive enhancement e.g. additional profits that a consumer gets), can strengthen specific attitudes and behaviour approved by a company/brand, and simultaneously marginalize or eliminate those that are disadvantageous for them (aversive enhancement). It would be also worth considering a possible reverse direction of that relation: stimuli from consumer as a determinant of companies/brands' behaviour, taking into account potential positive and aversive enhancements created by a consumer e.g. more frequent choice of brands that use solutions based on chatbots (bilingualism of a given model). While referring here to the Darwin's theory that was directed at the imperative of the survival of an individual and the 
imperative of the survival of the species, observed dataism enforces, in a natural way, mechanisms, both in a man-consumer and a company/brand related to the adjustment to volatile digital environment. What is also significant here is multiplicity of factors and components determining that process as e.g.: a degree of interest in digital technologies, sympathy for solutions based on them, socalled swarm intelligence, an extent to which new technologies are treated as a regular - indispensable element of everyday activities, including these related to marketing, status and prestige of individual technologies, activity in social media and a level of advancement of tools applied there, a degree of functionality of specific technologies or, at last, easiness to apply them in practice. As a result, interaction with human is the biggest test for machines in their ability to prove their usability.

At the stage of detailed studies on using chatbots in marketing and a range of their interaction between a man (consumer) and this technology a very useful model would undoubtedly be the classical TAM model. In spite of some criticism, it is one of the most popular research models in the area of acceptance of new technologies. External variables included in the model should concern both, activities realized by companies/brands in that area (e.g. the scope of using them in marketing practice, a level of advancement of individual solutions, their degree of functionality, etc.) as well as their user (in particular: age, sex, personality traits, interest in new technologies, previous experience in that area or sympathy for them). They definitely influence attitudes, intentions and behavior of consumers, which is of crucial importance in the processes of absorption and adaptation of this technology in marketing of post digital era.

However, while thinking about models of interaction between a consumer and digital technology, including chatbots and their application in marketing (Consumer - Chatbots Interactions), we should take into account, subsequently, multidimensionality of potential interactions (e.g. activities and their effects, individuality and collectivity of interactions, space generated only by a man, space generated only by a chatbot along with hybrid solutions) and treat them as complex adaptation models which consist of numerous interacting elements that can change in time as well as learn due to further interactions and experience. At the same time, they should in a holistic way consider a process of creating values for each party of such an interaction, taking into account the consumer typology because humans and machines need not only to coexist but also to colaborate. It is worth considering whether there are any situations in which consumer behaviour changes under the influence of digital technologies, yet, the 


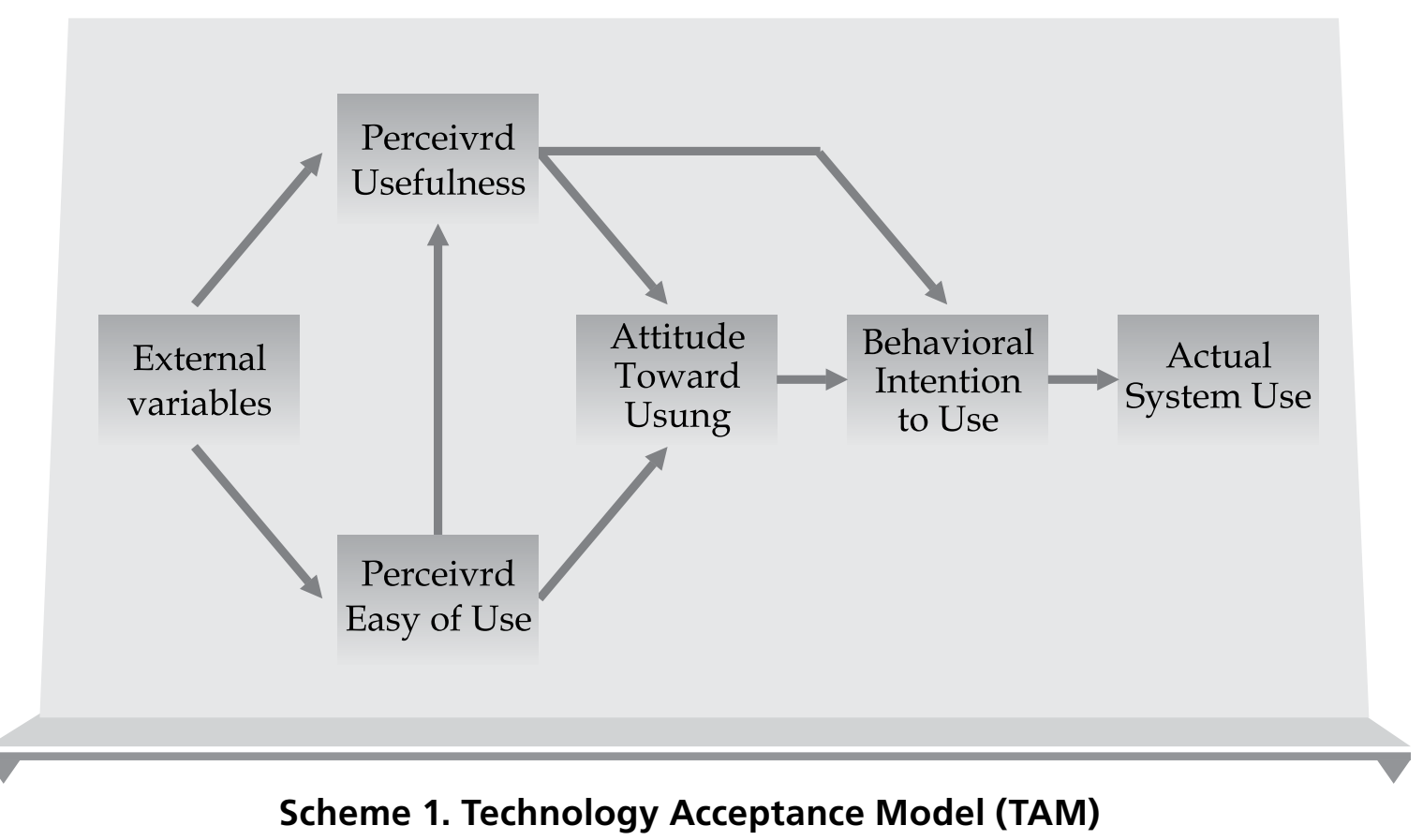

Source: F. Davis, R. Bagozzi, P. Warshaw (1989), User Acceptance Of Computer Technology: A Comparison Of Two Theoretical Models, "Management Science" Vol. 35, No. 8, pp. 982-1003

change is of temporary and transitional nature, and has no significant impact on their subsequent evolution and interaction with a company/brand. This will, however, require conducting research of both, survey nature and based on diverse experiments, including some ethnographic and phenomenological studies resulting from an actual interaction between a man and chatbots (affective reactions). Achieving a better understanding of the customers' needs and behaviours is very important step toward a successful digital transformation, which can help transform the customer experience (Borek, Reinold, 2016, p. 100). Chatbots have also the potential to offer a kinder, gentler style of interactions, thereby making it easier for human to accept machines as cognitive cohorts. In addition to supporting a man-machine interface. They can also assist humans in human-to human interactions (Sathi, 2016, p. ). It will be of crucial importance in terms of marketing strategies of companies and brands while influencing both, the methodology of an approach to consumer and the selection of instruments of impact and interactions at different levels: tentative, advanced, dynamic, optimized. 


\section{Conclusions}

Our intelligence evolved because it was useful for survival. As practiced by our species, it has enabled us not only to dominate the planet but to steadily improve the quality of our lives (Kurzweil 2016, p. 359). The increasingly widespread digital technologies become its specific extension that may multiply our - human possibilities if we fully understand what they are all about, and we will be able to predict their accompanying threats.

Chatbots become for companies/brands one of more and more popular and preferable channels of interactions with consumers. Thanks to them, clients begin to cooperate with brands in the same way as they cooperate with people, more and more informally, intuitionally and often in real time. Yet, perception of chatbots only in an instrumental way, as one of numerous tools available in the market, which can facilitate or optimize current marketing activities, does not adequately reflect their essence. It is definitely much more than just a technology. Equipped with personality and based on self-optimization mechanisms, they can become our faithful reflection in the future, the representation of what we are, which will be significant for further conversion of marketing. It will, however, require profound understanding of rules of interactions between consumers and chatbots.

Being the subject of dynamic digital transformation, marketing benefits from successive technologies, which allows companies/brands to be even more efficient in the process of maximization of broadly understood advantages. Efficiency of marketing of the future - an immediate reaction to a detected signal in a form of advice, offer, recommendation, accurate advertising or just a message that the consumer is important - will play a significant role. Promptness of an appropriate reaction will be the Holy Grail of modern marketing while proving an ability of synergic combination of data, technology, creativity, managerial efficiency as well as ethics and safety (Mazurek, 2018, p. 33).

\section{Summary}

\section{Chatbots in marketing}

The role of digital technologies, especially the Internet of Things (IoT) and Artificial Intelligence (AI), increasingly become a key element of diverse interactions between brands and consumers. Homo Cyber Oeconomicus, one of the potential stages of ongoing consumer's evolution, lives between processes of dehumanization of the surrounding world and humanization of 
digital technologies. While remaining in a constant contact with smart devices, systems and algorithms, they are looking for new values and meanings, which are a metaphor of their desires, fears and behaviors. As a result, the digital ecosystem, as an attempt to combine the humanism idea with technologization processes, poses new challenges to companies/brands, both concerning the quality of interactions with an increasingly digital consumer and tools used in that process. Chatbots can prove to be an interesting solution here, as their spectrum of potential areas of implementation in business systematically increases. The paper attempts to identify the influence of chatbots on marketing taking into account their role in Human-to-Machine interaction process. A part of these considerations is of the character of philosophical discourse on the role of that technology in human life, which is a starting point for the presentation of preliminary assumptions for a model of consumer-chatbot interaction (digital technology) in marketing activity of companies/brands.

Keywords: digital technologies, chatbots, consumer behavior, marketing.

\section{Streszczenie}

\section{Chatboty w marketingu}

Rola technologii cyfrowych, w tym w szczególności Internet of Things (IoT) i Artificial Intelligence (AI) staje coraz bardziej kluczowym elementem zróżnicowanych interakcji pomiędzy markami i konsumentami. Homo Cyber Oeconomicus, będący jednym z potencjalnych etapów trwającej ewolucji konsumenta, żyje między procesami dehumanizacji otaczającego go świata a humanizacji technologii cyfrowych. Pozostając w ciągłym kontakcie $z$ inteligentnymi urządzeniami, systemami i algorytmami poszukuje nowych wartości i znaczeń, stanowiących metaforę jego pragnień, obaw i zachowań. W efekcie digital ecosystem, będący próbązespoleniaideihumanizmuzprocesamitechnologizacjistawia przed firmami/markami nowe wyzwania, zarówno co do jakości realizowanych interakcji z coraz bardziej cyfrowym konsumentem, jak i narzędzi wykorzystywanych $\mathrm{w}$ tym procesie. Ciekawym rozwiązaniem mogą okazać się chatboty, których spektrum potencjalnych obszarów implementacji w biznesie systematycznie 
wzrasta. W artykule podjęto próbę zidentyfikowania wpływu chatbotów na marketing, ze szczególnym uwzględnieniem ich roli w procesie interakcji Human - to - Machine. Część prowadzonych rozważań ma charakter filozoficznego dyskursu nad rolą tej technologii w życiu człowieka, co stanowi punkt wyjścia do prezentacji wstępnych założeń modelu interakcji konsumenta i chatbotów (technologia cyfrowa) w aktywności marketingowej firm/marek.

\section{Słowa}

kluczowe: technologie cyfrowe, chatboty, zachowania konsumenckie, marketing.

JEL

Classification: M31

\section{References:}

1. Aigrain, P. (2012). Sharing. Culture and the Economy in the Internet Age, Amsterdam University Press, Amsterdam.

2. Barrat, J. (2015). Our final invention. Artificial Intelligence and the end of the human era, ST. Martin's Press, New York.

3. Benz, M., Meikle, G. (2018). The Internet of Things, Digital Media and Society Serie, UK.

4. Borek, A., Reinold, J. (2016). Marketing with smart machines. Customer Interaction in the the Algorithmic Economy, Executing Digital Publishing, Berlin.

5. Brynjolfsson, E., McAfee, A. (2014). The second machine age, W.W. Norton \& Co., New York, London.

6. Daugherty, P., Wilson, H. (2018). Human + Machine. Reimagining Work in the ahe of AI, Harvard Business Review Press, Boston, Massachusetts.

7. Davis F., Bagozzi R., Warshaw P. (1989), User Acceptance Of Computer Technology: A Comparison Of Two Theoretical Models, "Management Science" Vol. 35, No. 8.

8. Gregor, B., Kaczorowska-Spychalska, D. (2018). Marketing werze technologii cyfrowych, PWN, Warszawa.

9. Harari, Y. (2017). Homo Deus. A Brief History of Tomorrow, London:Vintage.

10. Kelly, K. (2017). Nieuniknione. Jak inteligentne technologie zmienia nasza przyszłość, Poltext, Warszawa.

11. Kotler, Ph., Kartajaya, H., Setiawan, I. (2018). Marketing 4.0. Moving from Traditional to Digital, Wiley John\&Sons Inc., USA.

12. Kurzweil, R. (2013). How to Create a Mind: The Secret of Human Thought Reveald, Penguin Books 2013, New York. 
13. Kurzweil, R. (2015). The singularity is near: when humans transcend biology, Viking Penguin, USA.

14. Lubian, F., Esteves, J. (2017). Value in a digital world, Palgrave MacMillan, Cham, Switzerland.

15. Przegalińska, A. (2016). Istoty wirtualne, Wydawnictwo Universitas. Kraków.

16. Saacolick, I. (2017). Driving Digital, American Management Association, New York.

17. Sathi, A. (2016). Cognitive (Internet of) Things, Collaboration to optimize action, Palgrave Macmillan, New York.

18. Sinclair, B. (2017). IoT Inc. How Your Company can use the Internet of Things to win in the outcome economy, McGraw Hill Education, New York - Toronto.

19. Skinner, Ch., (2018). Cyfrowi ludzie, Poltext, Warszawa.

20. SMSAPI (2018). Raport Komunikacja Marki - oczekiwania konsumenta, Warszawa.

21. State of Chatbots Report 2018, USA.

22. Tegmark, M. (2017). Life 3.0, Being Human in the age of artificial intelligence, Penguin Random House LLC, New York.

23. Walsh, T. (2017). It's alive! Artificial Intelligence from the logic piano to killer robots, La Trobe University Press, USA.

24. Weinman, J. (2015). Digital Disciplines, John Wiley \& Sons Inc., New Jersey.

25. Wuebben, J. (2017). Future Marketing. Winning in the prosumer age, Content Launch Press, USA.

26. https://chatbotsmagazine.com/chatbot-report-2018-global-trends-andanalysis-4d8bbe4d924b (access: 10.02.2019).

27. https://www.invespcro.com/blog/chatbots-customer-service (access date - 10.02.2019).

28. https://ducttapemarketing.com/chatbots-for-business (access date 10.02.2019).

29. https://www.forbes.com/sites/forbestechcouncil/2018/08/29/ chatbots-a-powerful-weapon-in-the-business-arsenal/\#41580cf64960 (access date - 09.02.2019). 